Trinity University

Digital Commons@ Trinity

Chemistry Faculty Research

Chemistry Department

$10-26-2011$

\title{
Nanomolar Binding of Peptides Containing Noncanonical Amino Acids by a Synthetic Receptor
}

Leigh A. Logsdon

TrinityUniversity, llogsdon@trinity.edu

Christopher L. Schardon

Trinity University

Vijayakumar Ramalingam

Trinity University, vramalin@trinity.edu

Sharon K. Kwee

Trinity University, skwee@trinity.edu

Adam R. Urbach

TrinityUniversity, aurbach@trinity.edu

Follow this and additional works at: https://digitalcommons.trinity.edu/chem_faculty

Part of the Chemistry Commons

\section{Repository Citation}

Logsdon, L. A., Schardon, C. L., Ramalingam, V., Kwee, S. K., \& Urbach, A. R. (2011). Nanomolar binding of peptides containing noncanonical amino acids by a synthetic receptor. Journal of the American Chemical Society, 133(42), 17087-17092. doi: 10.1021/ ja207825y

This Post-Print is brought to you for free and open access by the Chemistry Department at Digital Commons @ Trinity. It has been accepted for inclusion in Chemistry Faculty Research by an authorized administrator of Digital Commons @ Trinity. For more information, please contact jcostanz@trinity.edu. 


\section{Nanomolar Binding of Peptides Containing Noncanonical Amino Acids by a Synthetic Receptor}

Leigh A. Logsdon, Christopher L. Schardon, Vijayakumar Ramalingam, Sharon K. Kwee, and Adam R. Urbach*

Department of Chemistry, Trinity University, 1 Trinity Place, San Antonio, TX 78212

* to whom correspondence should be addressed: aurbach@ trinity.edu

ABSTRACT: This paper describes the molecular recognition of phenylalanine derivatives and their peptides by the synthetic receptor cucurbit[7]uril (Q7). The 4-t-butyl and 4-aminomethyl derivatives of phenylalanine (tBuPhe and AMPhe) were identified from a screen to have 20-30-fold higher affinity than phenylalanine for Q7. Placement of these residues at the $\mathrm{N}$-terminus of model tripeptides (X-Gly-Gly), resulted in no change in affinity for tBuPhe-Gly-Gly, but a remarkable 500-fold increase in affinity for AMPhe-Gly-Gly, which bound to Q7 with an equilibrium dissociation constant $\left(\mathrm{K}_{\mathrm{d}}\right)$ value of $0.95 \mathrm{nM}$ in neutral phosphate buffer. Structure-activity studies revealed that three functional groups work in a positively cooperative manner to achieve this extraordinary stability: 1) the N-terminal ammonium group; 2) the sidechain ammonium group; and 3) the peptide backbone. Addition of the aminomethyl group to Phe substantially improved the selectivity for peptide versus amino acid and for an $\mathrm{N}$-terminal vs. nonterminal position. Importantly, Q7 binds to N-terminal AMPhe several orders of magnitude more tightly than any of the canonical amino acid residues. The high affinity, single-site selectivity, and small modification in this system make it attractive for the development of minimal affinity tags. 


\section{Introduction}

The effort to design artificial receptors for peptides and proteins in aqueous solution has made substantial progress toward expanding the scope of receptor types, binding motifs, and potential targets. ${ }^{1}$ Realizing the promise of artificial protein receptors for applications in proteomics, medical diagnostics and drug delivery, however, will depend on finding ways to access desired targets with high fidelity and at low concentrations, often at or below $1 \mathrm{nM}$. Here we describe a way to achieve nanomolar binding by the synthetic receptor cucurbit[7]uril (Q7) via a simple chemical modification of the peptide.

Q7 is a water-soluble organic macrocycle first reported by Kimoon Kim and coworkers in $2000^{2}$ and since applied in numerous areas (e.g., waste remediation, sensing, catalysis, separations, drug delivery, electrochemistry, photochemistry, materials chemistry $)^{3}$ due to its high solubility and capacity to bind a wide range of guests with measurable equilibrium dissociation constant $\left(\mathrm{K}_{\mathrm{d}}\right)$ values in the $\mathrm{fM}-\mathrm{mM}$ range. ${ }^{4} \mathrm{We}$ are particularly interested in Q7 and related homologues for their ability to bind to peptides and proteins with strong selectivity for aromatic residues, especially at the $\mathrm{N}$-terminal position in the sequence. ${ }^{5}$ Sequence-specificity is mediated by the simultaneous inclusion of the aromatic sidechain within the nonpolar cavity of the cucurbituril and electrostatic attraction of the cationic N-terminal ammonium group with the negative dipoles of the carbonyl groups lining the entrances (portals) to the cavity (Figure 1). Recently our group has shown that this selectivity can translate from peptides to folded proteins via the unraveling of the terminus to accommodate Q7. ${ }^{6}$ Despite the excellent selectivity observed in these systems, the lowest $\mathrm{K}_{\mathrm{d}}$ values (for $\mathrm{N}$-terminal phenylalanine) are in the 
$0.1-1 \mu \mathrm{M}$ range. Such affinities by artificial receptors in aqueous solution are considered relatively high by current standards in the field, ${ }^{7}$ but a 100 -fold or better boost in affinity would significantly increase the viability of in vivo applications.

We hypothesized that small chemical modifications could be made to the sidechain of Phe that would provide additional intermolecular interactions to increase affinity for Q7, thus providing the additional stability required to achieve nanomolar binding. Herein we report a study in which a series of Phe derivatives were screened for binding to Q7, and two hits were identified and further explored in the context of peptides, ultimately yielding a peptide derivative that binds to Q7 with nanomolar affinity via the cooperation of multiple intermolecular interactions.

cucurbit[7]uril

(Q7)

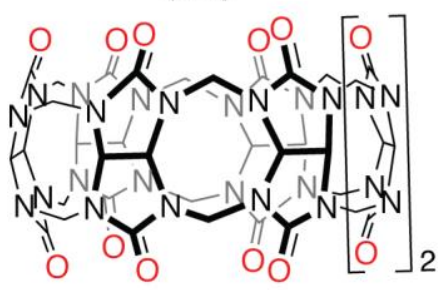

$\mathbf{R}=1: H(P h e)$

2: tBu (tBuPhe)

3: $\mathrm{CH}_{2} \mathrm{NH}_{2}$ (AMPhe)

4: $\mathrm{CH}_{3}$

5: $\mathrm{CF}_{3}$

6: $\mathrm{NH}_{2}$

7: $\mathrm{F}$

8: $\mathrm{Cl}$

9: $\mathrm{Br}$
Q7·1

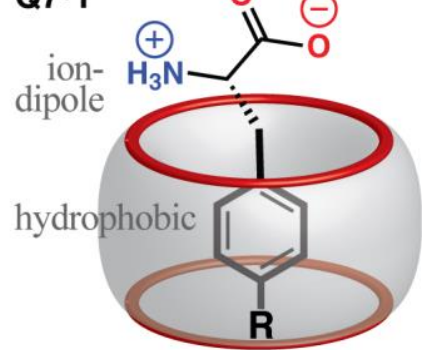

10:1

11: $\mathrm{NO}_{2}$

12: $\mathrm{OMe}$

13: $\mathrm{OH}$ (Tyr)

14: OAC

15: $\mathrm{N}_{3}$

16: $\mathrm{CN}$

17: $\mathrm{OPO}_{3} \mathrm{H}$

18: $\mathrm{CO}_{2} \mathrm{H}$
Peptides:

19: FGG

20: GFG

21: tBuPhe-Gly-Gly

22: AMPhe-Gly-Gly

23: Gly-AMPhe-Gly

Figure 1. Chemical formulas of the compounds in this study. The schematic at top right illustrates the stabilizing forces involved in the interaction of Phe with Q7; the red rings symbolize the negative dipole moments of the carbonyl groups lining both portals. 


\section{Results and Discussion}

Screening of Phenylalanine Derivatives. The series of 18 commercially available Lphenylalanine derivatives shown in Figure 1 was designed to represent a broad range of functionality, including hydrophobic and hydrophilic, electron-donating and withdrawing, cationic and anionic. All modifications are at the 4-position of the phenyl ring, which should be least sterically hindered based on reported crystal structures of Qn•Phe complexes. ${ }^{6,8}$ The series was screened for binding to Q7 using a fluorescence assay in which competitive displacement of the fluorescent dye acridine orange (AO) from the cavity of Q7 results in the quenching of fluorescence intensity. ${ }^{9}$ At a given concentration, a higher affinity analyte will displace more AO than a lower affinity analyte, and thus the relative extent of quenching is an excellent qualitative measure of relative binding affinity. A comparison of the extent of quenching ${ }^{10}$ of each derivative in the series (Figure 2) reveals some interesting phenomena: 1) compounds 2 and $\mathbf{3}$ show significantly more quenching than all other derivatives, including the parent phenylalanine 1; 2) compounds $\mathbf{1 7}$ and $\mathbf{1 8}$ show no measurable quenching; and 3) the remaining compounds show measurable quenching that is similar to or less than that of $\mathbf{1}$. In general, derivatives with electron withdrawing groups (e.g., halogens, $\mathrm{NO}_{2}, \mathrm{OMe}, \mathrm{OH}$, OAc, $\mathrm{CN}$ ) or anionic groups exhibited less quenching than $\mathbf{1}$. This result is consistent with electrostatic repulsion between the substituent and the carbonyl oxygens of Q7. Derivatives with hydrophobic or cationic groups exhibited quenching that is similar to or greater than 1. This result is consistent with the knowledge that cationic and hydrophobic groups stabilize guest interactions with cucurbiturils. 


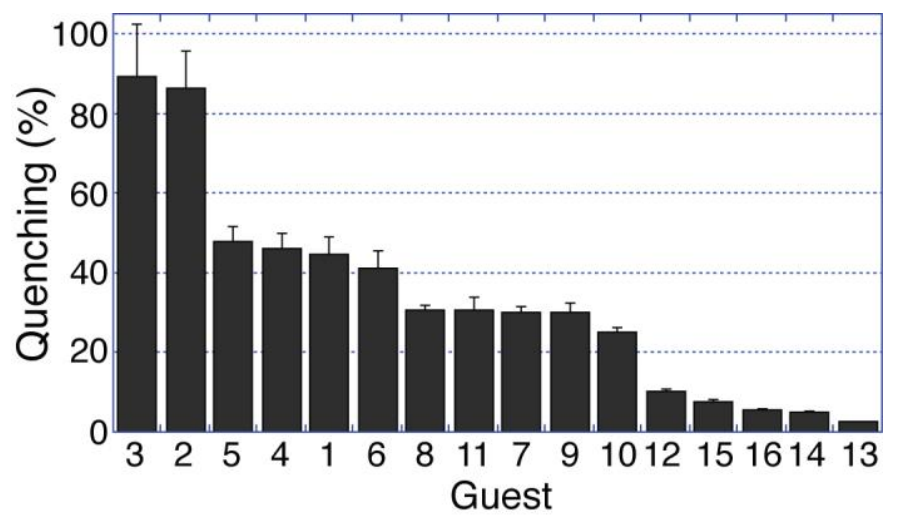

Figure 2. Bar plot comparing the relative fluorescence quenching induced by each of the 18 phenylalanine derivatives on competitive displacement of acridine orange from Q7 (20 $\mu \mathrm{M}$ amino acid, $2 \mu \mathrm{M}$ Q7, $2 \mu \mathrm{M}$ acridine orange, $10 \mathrm{mM}$ sodium phosphate, $\left.\mathrm{pH} 7.0,25^{\circ} \mathrm{C}\right) .{ }^{10}$ Error bars are standard deviations of three experiments. Qualitatively, the extent of quenching is directly related to the affinity of binding.

Characterization of Q7•tBuPhe (2) and Q7•AMPhe (3). In the qualitative screen of phenylalanine derivatives described above, we discovered that derivatives $\mathbf{2}$ and $\mathbf{3}$ bind more tightly than the parent 1 to Q7. In order to study these interactions in more detail, complexes of Q7 with amino acids $\mathbf{1}, \mathbf{2}$, and $\mathbf{3}$ were characterized by isothermal titration calorimetry (ITC), ${ }^{1} \mathrm{H}$ NMR spectroscopy, electrospray ionization (ESI) mass spectrometry, and molecular modeling.

ITC experiments were performed at $27^{\circ} \mathrm{C}$ in $10 \mathrm{mM}$ sodium phosphate, $\mathrm{pH} 7.0$ (see Supporting Information). All three amino acids showed a host:guest binding stoichiometry of 1:1, and 1:1 complexes were confirmed by ESI mass spectrometry (see Supporting Information). Thermodynamic values are listed in Table 1. Phe (1) bound with an equilibrium dissociation constant value of $8.7 \mu \mathrm{M}$, which is similar to previously reported values. ${ }^{4 b, 11}$ Derivatives 2 and 3 bound to Q7 with $K_{d}$ values 35-fold and 19-fold 
lower than 1, respectively. Therefore, the tert-butyl and aminomethyl substituents significantly stabilize the binding of Phe to Q7.

Table 1. Thermodynamic Data for Binding to Cucurbit[7]uril.

\begin{tabular}{lcccc}
\hline Guest & $\mathrm{K}_{\mathrm{d}}^{\mathrm{a}}$ & $\Delta \mathrm{G}^{\mathrm{b}}$ & $\Delta \mathrm{H}^{\mathrm{a}}$ & $-\mathrm{T} \Delta \mathrm{S}^{\mathrm{c}}$ \\
& $(\mathrm{M})$ & $(\mathrm{kcal} / \mathrm{mol})$ & $(\mathrm{kcal} / \mathrm{mol})$ & $(\mathrm{kcal} / \mathrm{mol})$ \\
\hline Phe (1) & $8.7( \pm 1.1) \times 10^{-6}$ & $-6.9( \pm 0.1)$ & $-7.6( \pm 0.2)$ & $0.7( \pm 0.1)$ \\
tBuPhe (2) & $2.5( \pm 0.6) \times 10^{-7}$ & $-9.1( \pm 0.2)$ & $-14.5( \pm 0.1)$ & $5.4( \pm 0.2)$ \\
AMPhe (3) & $4.6( \pm 0.1) \times 10^{-7}$ & $-8.7( \pm 0.1)$ & $-4.2( \pm 0.1)$ & $-4.5( \pm 0.1)$ \\
Phe-Gly-Gly (19) & $3.1( \pm 0.8) \times 10^{-7}$ & $-9.0( \pm 0.3)$ & $-13.4( \pm 0.4)$ & $4.4( \pm 0.3)$ \\
Gly-Phe-Gly (20) & $4.3( \pm 0.1) \times 10^{-6}$ & $-7.4( \pm 0.1)$ & $-9.8( \pm 0.1)$ & $2.4( \pm 0.1)$ \\
tBuPhe-Gly-Gly (21) & $2.1( \pm 0.3) \times 10^{-7}$ & $-9.2( \pm 0.2)$ & $-16.2( \pm 0.5)$ & $7.1( \pm 0.3)$ \\
AMPhe-Gly-Gly (22) & $9.5( \pm 1.5) \times 10^{-10}$ & $-12.4( \pm 0.2)$ & $-14.2( \pm 0.2)$ & $1.8( \pm 0.2)$ \\
Gly-AMPhe-Gly (23) & $5.1( \pm 0.2) \times 10^{-7}$ & $-8.6( \pm 0.1)$ & $-8.2( \pm 0.1)$ & $-0.5( \pm 0.1)$
\end{tabular}

${ }^{a}$ Mean values measured from at least three ITC experiments at $27{ }^{\circ} \mathrm{C}$ in $10 \mathrm{mM}$ sodium phosphate, $\mathrm{pH}$ 7.0. Standard deviations are given in parentheses. ${ }^{\mathrm{b}}$ Gibbs free energy values calculated from $K_{a}$ values. Standard deviations for $\Delta G$ values were calculated as the relative error observed in $\mathrm{K}_{\mathrm{a}}$, due to their relationship by a natural logarithm. ${ }^{\mathrm{c}}$ Entropic contributions to $\Delta \mathrm{G}$ calculated from $\mathrm{K}_{\mathrm{a}}$ and $\Delta \mathrm{H}$ values, with error propagated from that of $\mathrm{K}_{\mathrm{a}}$ and $\Delta \mathrm{H}$.

Molecular modeling of the Q7•2 and Q7•3 complexes (Figure 3) shows the aromatic sidechains bound within the cavity of Q7, and it is clear that $\mathbf{3}$ is bound much more deeply than 2 , threading all the way through the host and allowing the aminomethyl sidechain and $\mathrm{N}$-terminal ammonium groups to interact simultaneously with opposite carbonyl portals. In fact, the model of Q7•2 shows the tert-butyl group in the center of the Q7 cavity, allowing the ammonium group barely enough room to fold over and make 
contact with the portal. The ${ }^{1} \mathrm{H}$ NMR spectra of tBuPhe (2) and Q7•2 show a strong (1.06 ppm) upfield perturbation in chemical shift of the aromatic hydrogens closest to the tertbutyl group $\left(\mathrm{H}_{\mathrm{b}}\right.$ in Figure $\left.3 \mathrm{a}\right)$ but only a modest $(0.13 \mathrm{ppm})$ upfield perturbation in the other aromatic peak $\left(\mathrm{H}_{\mathrm{a}}\right)$ upon binding to Q7. ${ }^{12}$ The tert-butyl peak also shifted considerably (0.74 ppm) upfield (see Supporting Information). By contrast, both aromatic peaks in the spectrum of $\mathbf{3}$ shift substantially (0.71-0.78 ppm) upfield upon binding to Q7. These data corroborate the calculated models and indicate that the aromatic ring of $\mathbf{3}$ is fully buried inside the cavity of Q7, whereas only half the ring and the tert-butyl group of $\mathbf{2}$ is buried. 

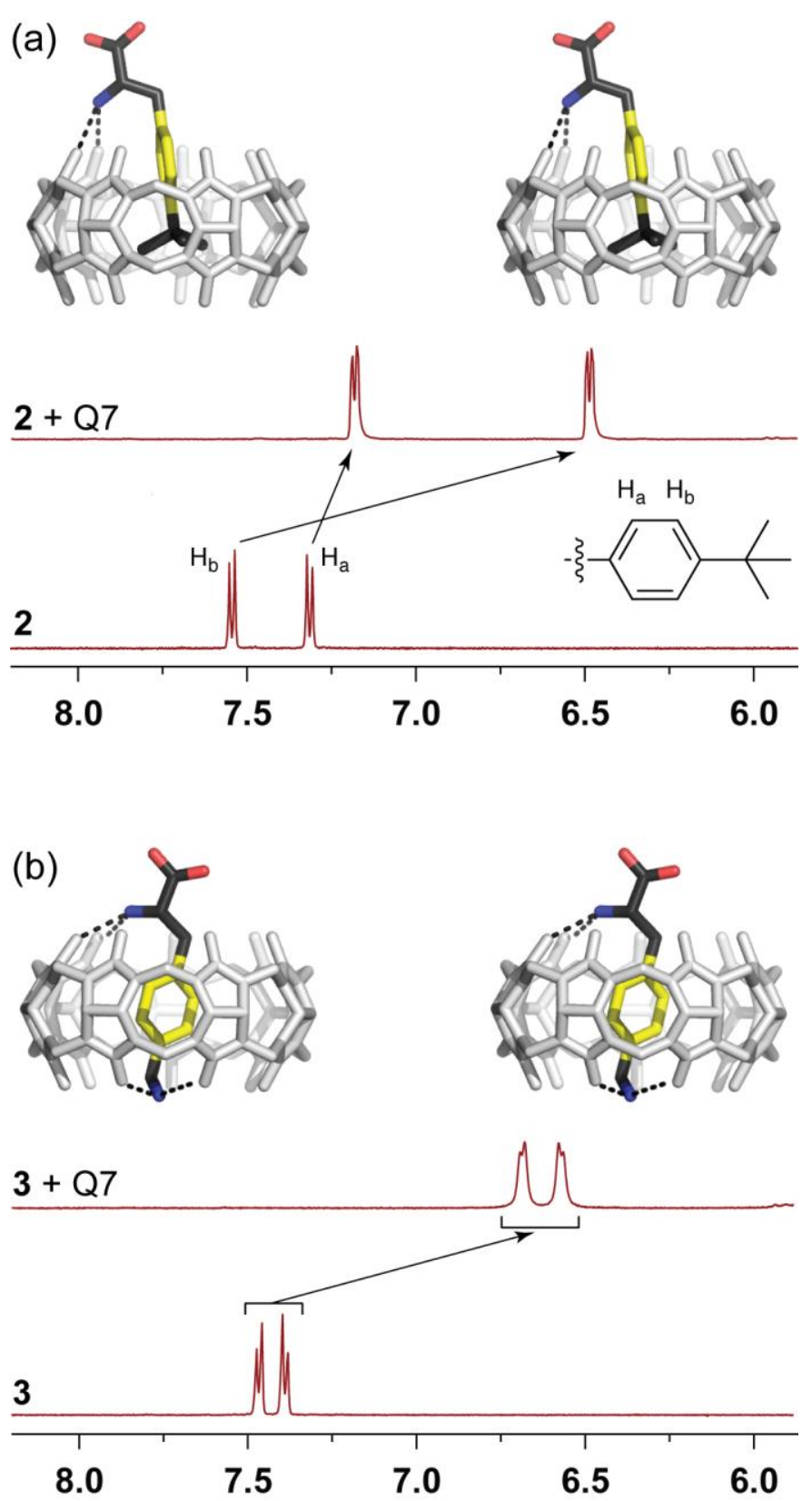

Figure 3. (top) Computational model using a molecular mechanics (MMFF) forcefield in a continuum solvent model, and (bottom) the aromatic region of the $500 \mathrm{MHz}{ }^{1} \mathrm{H}$ NMR spectra of (a) tBuPhe (2) and (b) AMPhe (3) in the presence and absence of Q7. All analytes were at a concentration of $2 \mathrm{mM}$. Spectra were acquired at $25^{\circ} \mathrm{C}$ in deuterium oxide solution containing $10 \mathrm{mM}$ sodium phosphate, $\mathrm{pH}$ 7.4. 
Peptides Containing N-terminal AMPhe and tBuPhe. It is known that peptides with phenylalanine at the N-terminus bind more stably to cucurbiturils than the corresponding amino acids. ${ }^{5}$ Therefore, we hypothesized that tBuPhe and AMPhe residues, when placed at the respective N-termini of peptides, should also boost the affinity to Q7. To test this hypothesis, peptides $\mathbf{2 1}$ (tBuPhe-Gly-Gly-CONH${ }_{2}$ ) and 22 (AMPhe-Gly-Gly-CONH ), along with the unmodified parent peptide 19 (Phe-Gly-Gly$\mathrm{CONH}_{2}$ ), were synthesized and their binding to Q7 characterized in detail. All peptides contain a C-terminal primary amide for synthetic convenience and to eliminate any effect from the C-terminal charge.

Thermodynamic binding data for peptides 19, 21, and 22 (Table 1) were acquired using isothermal titration calorimetry at $27^{\circ} \mathrm{C}$ in $10 \mathrm{mM}$ sodium phosphate, $\mathrm{pH}$ 7.0. A 1:1 (peptide:Q7) binding stoichiometry was observed in all experiments, and 1:1 complexes were verified by ESI mass spectrometry (see Supporting Information). PheGly-Gly (19) bound to Q7 with a similar $\mathrm{K}_{\mathrm{d}}$ value $(0.31 \mu \mathrm{M})$ as its previously reported analogue with carboxylate terminus $(0.36 \mu \mathrm{M}),{ }^{6}$ and thus a 28 -fold gain in affinity versus Phe (1). We were surprised, however, to find that peptide 21, which contains an Nterminal tBuPhe residue, bound to Q7 with the same affinity as the corresponding amino acid $\mathbf{2}$, and thus no boost in stability for incorporation into a peptide.

By contrast, peptide 22, containing an N-terminal AMPhe residue, bound to Q7 with a $\mathrm{K}_{\mathrm{d}}$ value of $0.95 \mathrm{nM}$, which is $0.20 \%$ of the corresponding amino acid $\mathbf{3}$, and thus a 500-fold boost in affinity for incorporation into a peptide. Due to limitations in signal:noise, it was impossible to measure this value by direct titration. We used a 
competitive binding titration in the presence of 100-fold excess 1 to bring the observed equilibrium constant within the dynamic range of the instrument (Figure 4), while satisfying the assumptions required for this experiment (see Supporting Information for derivation). The exceptional stability of the Q7•22 complex is perhaps not surprising when considering the somewhat analogous Q7•bis(pyridinium)-1,4-xylylene complex, which binds with a $\mathrm{K}_{\mathrm{d}}$ value of $1.8 \times 10^{9} \mathrm{M}^{-1} .^{13}$ In the context of peptide recognition in aqueous solution, however, it is remarkable that such a stable complex can be achieved via the addition of only two heavy atoms to a peptide.

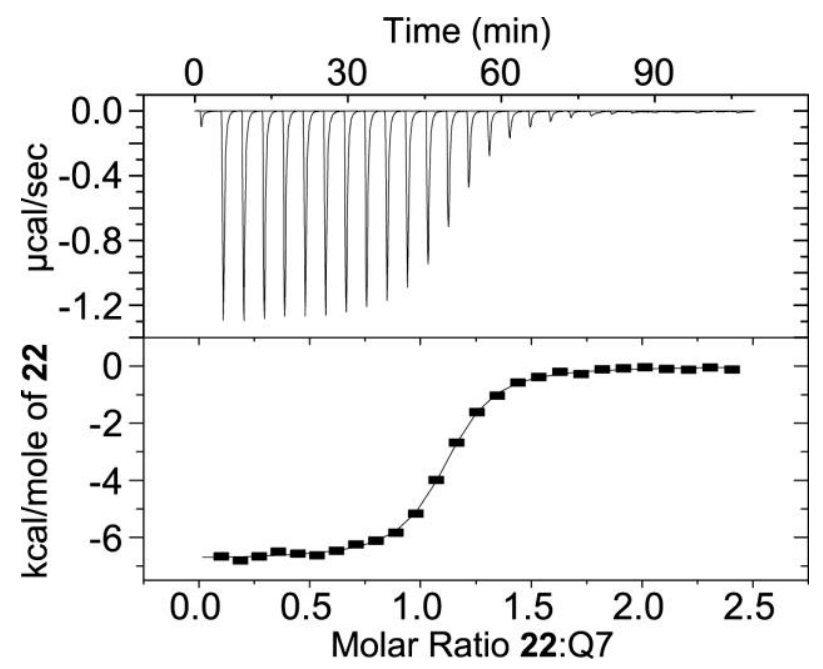

Figure 4. Isothermal titration calorimetry of AMPhe-Gly-Gly (22) binding to Q7. The experiment was carried out at $27^{\circ} \mathrm{C}$ in $10 \mathrm{mM}$ sodium phosphate, $\mathrm{pH} 7.0$, and in the presence of 100 -fold excess phenylalanine as a weak competitor. The peaks in the plot of power vs. time (top) were integrated to yield data for enthalpy vs. molar ratio of peptide:Q7 (bottom). The enthalpy data were fit to a binary equilibrium model to derive an apparent equilibrium constant, which was used to calculate the high affinity of peptide 22.

The ${ }^{1} \mathrm{H}$ NMR spectra of peptides 21 and 22 in the presence and absence of Q7 mimic those of the corresponding amino acids $\mathbf{2}$ and $\mathbf{3}$, showing the same trends in the 
perturbation of chemical shift in the aromatic and upfield protons (see Supporting Information). We believe that the lack of affinity gain in tBuPhe-containing peptide $\mathbf{2 1}$ vs. its corresponding amino acid $\mathbf{2}$ is due to the incomplete burial of the aromatic sidechain of $\mathbf{2 1}$ and thus the inability of the $\mathrm{N}$-terminal ammonium group and the peptide chain to make simultaneous contact with the Q7 portal oxygens. The deeper burial of the sidechain of AMPhe-containing peptide $\mathbf{2 2}$ and its corresponding amino acid $\mathbf{3}$ should allow the peptide backbone to interact directly with carbonyl groups on the portal, likely forming strong ion-dipole interactions as observed in previously reported crystal structures of Qn•Phe complexes. ${ }^{6,8}$

Sequence-Selectivity. Cucurbiturils are known recognize N-terminal phenylalanine, tryptophan, and tyrosine sequence-selectively. ${ }^{5}$ In order to study the influence of the aminomethyl group, we synthesized peptide 23 (Gly-AMPhe-Gly-CONH 2 ) and the corresponding unmodified control peptide 20 (Gly-Phe-Gly-CONH 2$)$ and characterized their binding to Q7. Both host:guest complexes bound in a 1:1 stoichiometry as observed by ITC and ESI mass spectrometry (see Supporting Information). Thermodynamic binding data (Table 1) revealed a modest sequence-selectivity of 13-fold for unmodified N-terminal Phe (19) vs. nonterminal Phe (20). ${ }^{14}$ By contrast, the analogous peptides containing an aminomethyl group revealed a remarkable 550-fold selectivity for the Nterminus versus nonterminal position. Therefore, Q7 recognizes N-terminal AMPhe with excellent selectivity for the peptide sequence, the aminomethyl modification, and the corresponding amino acid. 


\section{Positive Cooperativity and Other Thermodynamic Considerations. A comparison}

of the relative free energies of binding to Q7 $(\Delta \Delta \mathrm{G})$ of compounds $\mathbf{1}, \mathbf{3}, \mathbf{1 9}, \mathbf{2 0}, \mathbf{2 2}$, and

23 is shown in Figure 5. All compounds have a common aromatic sidechain but differ in their N-terminal group, C-terminal group, and/or sidechain modification, all of which can influence the extent of electrostatic interaction with the carbonyl oxygens on the portal(s) of Q7. Phenylalanine (1) has an attractive $\mathrm{N}$-terminal ammonium group and a repulsive C-terminal carboxylate. The peptide Phe-Gly-Gly (19) binds to Q7 $2.0 \mathrm{kcal} / \mathrm{mol}$ more stably than 1. Both have an attractive N-terminal ammonium group, so the energetic difference is likely due to replacement of the repulsive C-terminal carboxylate with an attractive peptide chain. AMPhe $(3)$ binds to Q7 $1.8 \mathrm{kcal} / \mathrm{mol}$ more stably than $\mathbf{1}$. Both are amino acids, so the difference is likely due to the additional interaction afforded by the positively charged sidechain interacting with the opposite Q7 portal. If both of these structural modifications were made simultaneously to Phe, the result would be AMPheGly-Gly (22), which has an aminomethyl sidechain, a peptide tail, and an N-terminal ammonium group. One may expect, therefore, that 22 would bind to Q7 $\sim 3.8 \mathrm{kcal} / \mathrm{mol}$ more stably than $\mathbf{1}$ (the sum of the two energies). Surprisingly, we find that $\mathbf{2 2}$ binds to Q7 $5.5 \mathrm{kcal} / \mathrm{mol}$ more stably than $\mathbf{1}$. Therefore, the aminomethyl sidechain, the peptide tail, and the N-terminal ammonium group work together in a positively cooperative (synergistic) manner to provide an unexpectedly large energetic stabilization. 


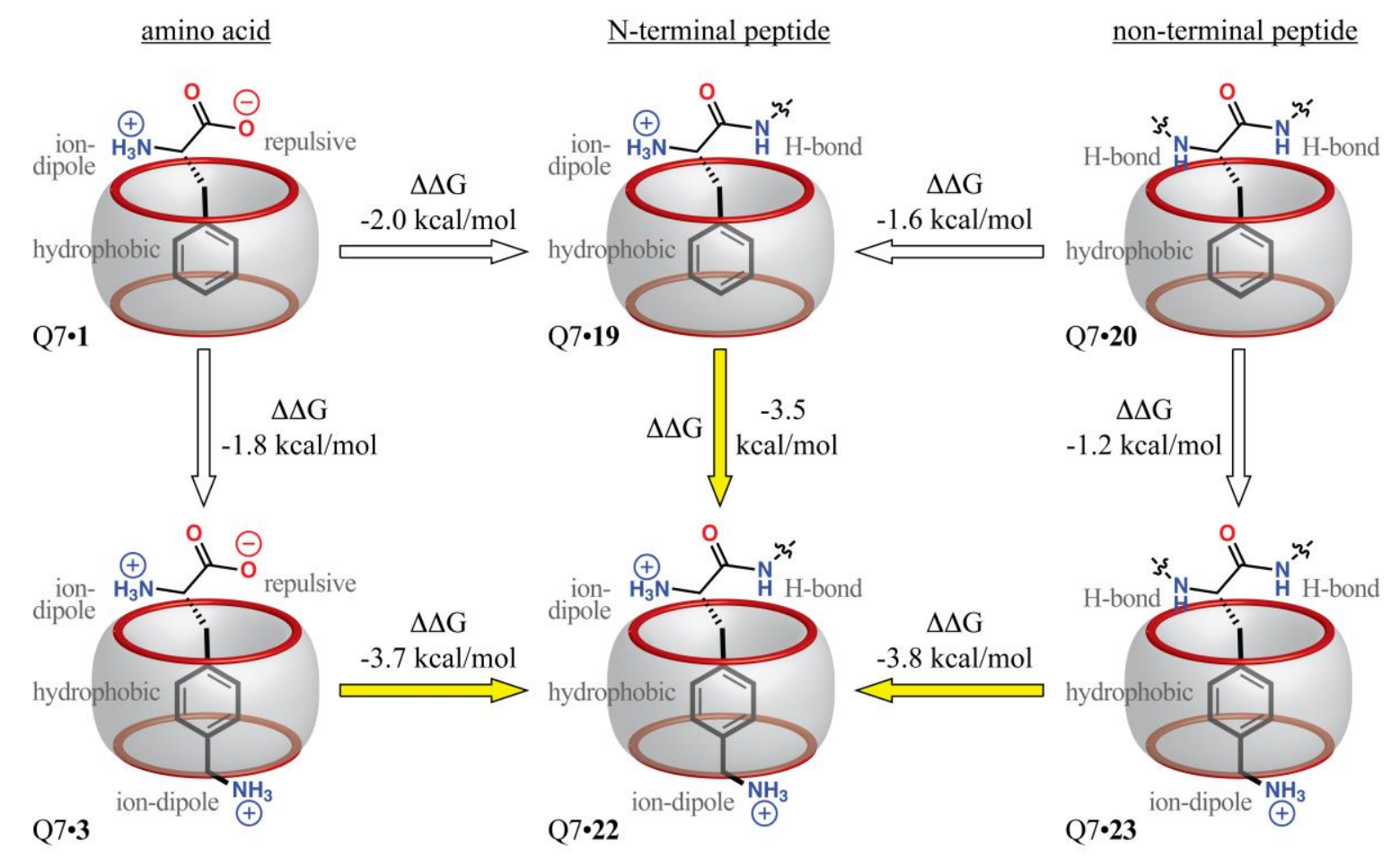

Figure 5. Illustration of the relative free energies of binding $(\Delta \Delta \mathrm{G})$ to $\mathrm{Q} 7$ for compounds $\mathbf{1 , 3}, \mathbf{1 9}, \mathbf{2 0}, \mathbf{2 2}$, and 23, with schematics highlighting the possible differences in interactions that produce these changes. Starting from the upper left and right corners, each arrow adds an additional interaction, ultimately producing an ultrastable complex containing several stabilizing factors that work together synergistically.

By analogy, we can start with Gly-Phe-Gly (20), which lacks an N-terminal ammonium group but has a peptide tail C-terminal to the aromatic sidechain. Peptide Phe-Gly-Gly (19) binds to Q7 $1.6 \mathrm{kcal} / \mathrm{mol}$ more stably than $\mathbf{2 0}$. Both compounds maintain the peptide tail, so the energetic difference is likely due to the attractive ammonium group of 19. Peptide 23 binds to Q7 $1.2 \mathrm{kcal} / \mathrm{mol}$ more stably than $\mathbf{2 0}$. Both have peptide groups emanating from both sides of the aromatic residue, and thus the energetic difference is likely due to the attractive aminomethyl sidechain. If both of these structural modifications were made simultaneously to Gly-Phe-Gly (20), the result would 
be AMPhe-Gly-Gly (22), which has an aminomethyl sidechain, an N-terminal ammonium group, and a peptide tail. One may expect, therefore, that $\mathbf{2 2}$ would bind to Q7 $2.8 \mathrm{kcal} / \mathrm{mol}$ more stably than 1 (the sum of the two energies). Just like the above example, however, we find that $\mathbf{2 2}$ binds to Q7 $5.0-5.1 \mathrm{kcal} / \mathrm{mol}$ more stably than $\mathbf{2 0}$. Therefore, the aminomethyl sidechain, the $\mathrm{N}$-terminal ammonium group, and the peptide tail work synergistically to stabilize the binding of $\mathbf{2 2}$ to Q7.

Enthalpy and Entropy. Figure 6 shows a plot of the entropic vs. enthalpic contributions to the free energy of binding to Q7 for all eight compounds in Table 1. What is immediately apparent is the straight line fit, which was applied purposely to only the five data points plotted as filled circles. This extraordinarily linear $\left(\mathrm{R}^{2}>0.999\right)$ correlation shows a consistent compensation of enthalpic gain with entropic loss among the five compounds with very similar affinities in the $0.21-0.46 \mu \mathrm{M}$ range. Of the remaining three compounds, two have lower affinity (1 and $\mathbf{2 0})$ and lie above line with less favorable enthalpy and entropy, while one has much higher affinity (22) and lies below the line with more favorable enthalpy and entropy. We do not claim to understand this phenomenon, but it is interesting to observe that the two compounds lying above the line, Phe (1) and Gly-Phe-Gly (20), have the least number of stabilizing interactions as discussed in the section above and in Figure 5. Similarly, Phe-Gly-Gly (19), AMPhe (3), and Gly-AMPhe-Gly (23), which lie on the line, have one additional stabilizing interaction. Finally, AMPhe-Gly-Gly (22), which lies below the line, has the two additional stabilizing interactions. Collectively, the thermodynamic and spectroscopic data presented here emphasizes the importance of four groups for the binding of Q7 to 
AMPhe-Gly-Gly (22): the aromatic sidechain, the sidechain aminomethyl group, the peptide backbone, and the $\mathrm{N}$-terminal ammonium group. This complex provides a rare example of cooperative interaction among multiple functional groups to achieve extraordinary stability.

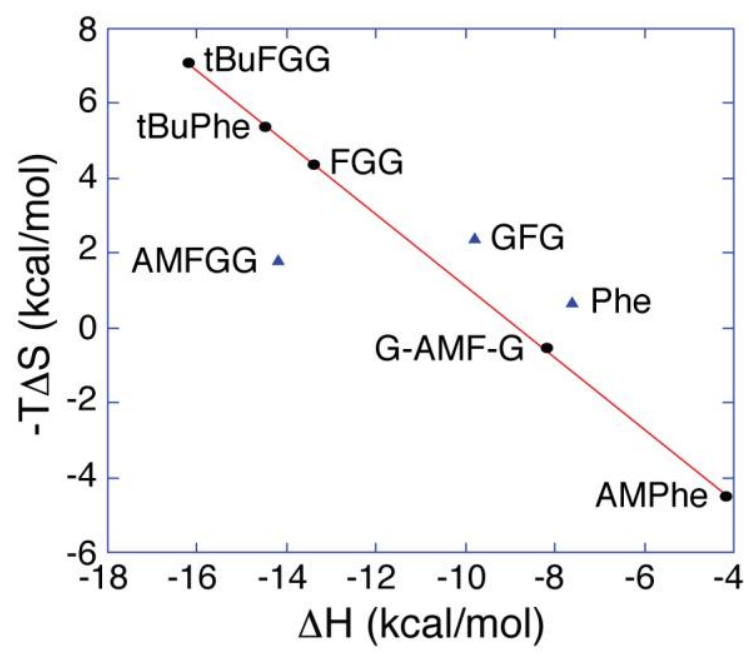

Figure 6. Plot of the entropic vs. the enthalpic contributions to the free energy of binding to Q7 for the series of eight compounds studied by ITC. The straight line is fit only to the data points represented as circles.

\section{Conclusions}

This is the first example of high-affinity, site-specific recognition of a peptide containing a noncanonical amino acid by a synthetic receptor. We find that adding an aminomethyl group to $\mathrm{N}$-terminal Phe yields a 500-fold increase in binding affinity for Q7, a $K_{d}$ value of $0.95 \mathrm{nM}$, and selectivity versus other sites and canonical residues in excess of $3.5 \mathrm{kcal} / \mathrm{mol}$. This combination of affinity and selectivity makes it worthwhile to consider whether binding to N-terminal AMPhe would be selective in a proteomic context and thus useful as an affinity tag for protein purification. In this capacity, AMPhe 
should have certain advantages compared to other protein tags, either genetically encoded (e.g., His, FLAG, GST) ${ }^{15}$ or chemically introduced (e.g., biotin or

bis(dimethylamino)ferrocene derivatives ${ }^{4 c}$ ), because it replaces existing Phe residues thus requiring less genetic modification, it is a much smaller addition to the protein, it enables elution from the affinity matrix under a wide range of conditions (native and denaturing) using a competitive guest, and it doesn't require the introduction of other proteins such as antibodies or streptavidin. Higher affinity guests for Q7 exist, including several ferrocene and adamantyl derivatives, ${ }^{4 \mathrm{~b}, 11 \mathrm{~b}}$ and others have shown that protein-ferrocene conjugates can be selectively isolated from cell extracts. ${ }^{16}$ Compared to such conjugates, AMPhe has the chief advantage that, with only two additional heavy atoms, it still closely resembles native Phe, and thus there is a good chance that it can be metabolically incorporated into proteins as an affinity tag in vivo. ${ }^{17}$

Supporting Information. Experimental details, isothermal titration calorimetry data, ${ }^{1} \mathrm{H}$ NMR spectra and limiting chemical shifts for the modified phenylalanine sidechains, mass spectra, and a derivation of the competitive binding analysis.

Acknowledgement. We thank Frank Truong for helpful discussions. Financial support from the National Science Foundation (CHE-0748483), the Welch Foundation (W-1640), and the Henry Dreyfus Teacher-Scholar Awards Program is gratefully acknowledged.

\section{References}

(1) (a) Still, W. C. Acc. Chem. Res. 1996, 29, 155-163. (b) Breslow, R.; Yang, Z.; Ching, R.; Trojandt, G.; Odobel, F. J. Am. Chem. Soc. 1998, 120, 3536-3537. (c) 
Sirish, M.; Schneider, H.-J. Chem. Comm. 1999, 907-908. (d) Peczuh, M. W.; Hamilton, A. D. Chem. Rev. 2000, 100, 2479-2493. (e) Nowick, J. S.; Chung, D. M. Angew. Chem. Int. Ed. 2003, 42, 1765-1768. (f) Tashiro, S.; Tominaga, M.; Kawano, M.; Therrien, B.; Ozeki, T.; Fujita, M. J. Am. Chem. Soc. 2005, 127, 4546-4547. (g) Wright, A. T.; Griffin, M. J.; Zhong, Z. L.; McCleskey, S. C.; Anslyn, E. V.; McDevitt, J. T. Angew. Chem. Int. Ed. 2005, 44, 6375-6378. (h) Yin, H.; Hamilton, A. D. Angew. Chem. Int. Ed. 2005, 44, 4130-4163. (i) Bush, M. E.; Bouley, N. D.; Urbach, A. R. J. Am. Chem. Soc. 2005, 127, 14511-14517. (j) Schmuck, C. Coord. Chem. Rev. 2006, 250, 3053-3067. (k) Cummings, C. G.; Hamilton, A. D. Curr. Opin. Chem. Biol. 2010, 14, 341-346. (l) Dutt, S.; Wilch, C.; Schrader, T. Chem. Comm. 2011, 47, 5376-5383. (m) Hochdorffer, K.; Marz-Berberich, J.; Nagel-Steger, L.; Epple, M.; Meyer-Zaika, W.; Horn, A. H. C.; Sticht, H.; Sinha, S.; Bitan, G.; Schrader, T. J. Am. Chem. Soc. 2011, 133, 43484358.

(2) Kim, J.; Jung, I.-S.; Kim, S.-Y.; Lee, E.; Kang, J.-K.; Sakamoto, S.; Yamaguchi, K.; Kim, K. J. Am. Chem. Soc. 2000, 122, 540-541.

(3) Nau, W. M.; Scherman, O. A. Israel J. Chem. 2011, 51, 492-494.

(4) (a) Lagona, L.; Mukhopadhyay, P.; Chakrabarti, S.; Isaacs, L. Angew. Chem. Int. Ed. 2005, 44, 4844-4870. (b) Liu, S.; Ruspic, C.; Mukhopadhyay, P.; Chakrabarti, S.; Zavalij, P. Y.; Isaacs, L. J. Am. Chem. Soc. 2005, 127, 1595915967. (c) Ko, Y. H.; Hwang, I.; Lee, D.-W.; Kim, K. Israel J. Chem. 2011, 51, 506-514.

(5) Urbach, A. R.; Ramalingam, V. Israel J. Chem. 2011, 51, 664-678.

(6) Chinai, J. M.; Taylor, A. B.; Ryno, L. M.; Hargreaves, N. D.; Morris, C. A.; Hart, P. J.; Urbach, A. R. J. Am. Chem. Soc. 2011, 133, 8810-8813.

(7) Houk, K. N.; Leach, A. G.; Kim, S. P.; Zhang, X. Angew. Chem. Int. Ed. 2003, 42, 4872-4897.

(8) Heitmann, L. M.; Taylor, A. B.; Hart, P. J.; Urbach, A. R. J. Am. Chem. Soc. 2006, 128, 12574-12581.

(9) Shaikh, M.; Mohanty, J.; Singh, P. K.; Nau, W. M.; Pal, H. Photochem. Photobiol. Sci. 2008, 7, 408-414.

(10) $\%$ quenching $=\left(I_{\text {analyte }}-I_{\min }\right) /\left(I_{\max }-I_{\min }\right)$, where $I_{\text {analyte }}$ is the intensity of $20 \mu \mathrm{M}$ Phe derivative $+2 \mu \mathrm{MQ} 7+2 \mu \mathrm{M} \mathrm{AO}, \mathrm{I}_{\max }$ is the intensity of $2 \mu \mathrm{M} \mathrm{Q7}+2 \mu \mathrm{M} \mathrm{AO}$, and $\mathrm{I}_{\min }$ is the intensity of $2 \mu \mathrm{M}$ AO.

(11) (a) Cong, H.; Tau, L.-L.; Yu, Y.-H.; Yang, F.; Du, Y.; Xue, S.-F.; Tao, Z. Acta Chim. Sin. 2006, 64, 989-996. (b) Rekharsky, M. V.; Mori, T.; Yang, C.; Young, H. K.; Selvapalam, N.; Kim, H.; Sobransingh, D.; Kaifer, A. E.; Liu, S.; Isaacs, L.; Chen, W.; Moghaddam, S.; Gilson, M. K.; Kim, O.; Inoue, Y. Proc. Natl. Acad. Sci. 2007, 104, 20737-20742.

(12) Assignments were made using the 2D ROESY spectra of 2 and Q7•2 (see Supporting Information).

(13) Sindelar, V.; Moon, K.; Kaifer, A. E. Organic Letters 2004, 6, 2665-2668.

(14) This 13 -fold selectivity is significantly less than the 68 -fold selectivity previously observed $^{6}$ for the analogous carboxylate-terminated peptides, likely due to weaker repulsion between the carbonyl oxygens of Q7 and the neutral C-terminus of GlyPhe-Gly- $\mathrm{CONH}_{2}$ (20). 
(15) Lichty, J. J.; Malecki, J. L.; Agnew, H. D.; Michelson-Horowitz, D. J.; Tan, S. Protein Expr. Purif. 2005, 41, 98-105.

(16) Lee, D.-W.; Park, K. M.; Banerjee, M.; Ha, S. H.; Lee, T.; Suh, K.; Paul, S.; Jung, H.; Kim, J.; Selvapalam, N.; Ryu, S. H.; Kim, K. Nature Chem. 2011, 3, 154-159.

(17) (a) Johnson, J. A.; Lu, Y. Y.; Van Deventer, J. A.; Tirrell, D. A. Curr. Opin. Chem. Biol. 2010, 14, 774-780. (b) Kirshenbaum, K.; Carrico, I. S.; Tirrell, D. A. Chembiochem 2002, 3, 235-237. 
Table of Contents Graphic:

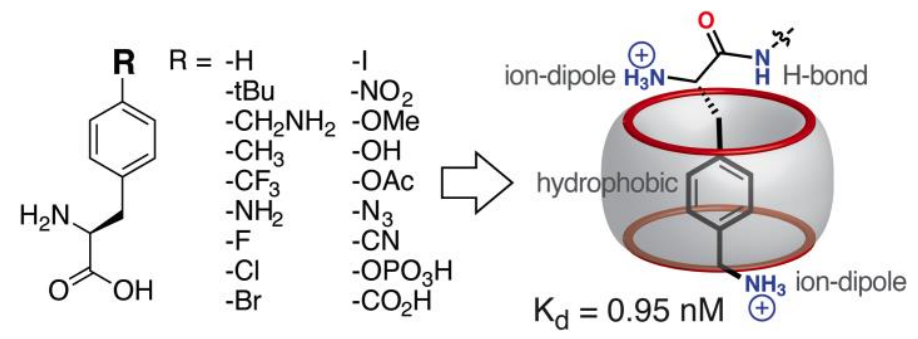

